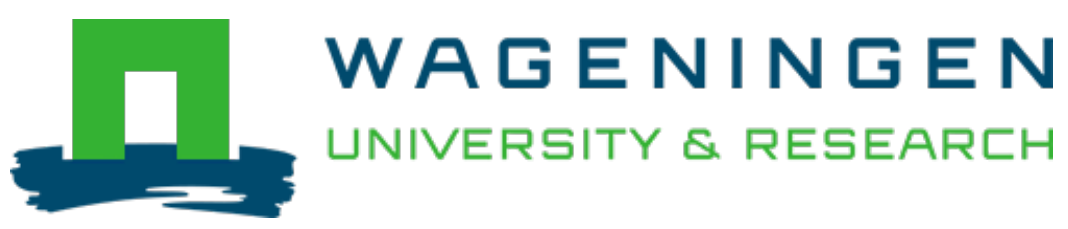

\title{
Effects of Digital Learning Materials on nursing students' mathematics learning, self-efficacy, and task value in vocational education
}

Nurse Education in Practice

Zwart, Diana P.; Noroozi, Omid; Luit, Johannes E.H.; Goei, Sui Lin; Nieuwenhuis, Arjen

https://doi.org/10.1016/j.nepr.2020.102755

This article is made publicly available in the institutional repository of Wageningen University and Research, under the terms of article $25 \mathrm{fa}$ of the Dutch Copyright Act, also known as the Amendment Taverne. This has been done with explicit consent by the author.

Article 25 fa states that the author of a short scientific work funded either wholly or partially by Dutch public funds is entitled to make that work publicly available for no consideration following a reasonable period of time after the work was first published, provided that clear reference is made to the source of the first publication of the work.

This publication is distributed under The Association of Universities in the Netherlands (VSNU) 'Article $25 \mathrm{fa}$ implementation' project. In this project research outputs of researchers employed by Dutch Universities that comply with the legal requirements of Article $25 \mathrm{fa}$ of the Dutch Copyright Act are distributed online and free of cost or other barriers in institutional repositories. Research outputs are distributed six months after their first online publication in the original published version and with proper attribution to the source of the original publication.

You are permitted to download and use the publication for personal purposes. All rights remain with the author(s) and / or copyright owner(s) of this work. Any use of the publication or parts of it other than authorised under article $25 \mathrm{fa}$ of the Dutch Copyright act is prohibited. Wageningen University \& Research and the author(s) of this publication shall not be held responsible or liable for any damages resulting from your (re)use of this publication.

For questions regarding the public availability of this article please contact openscience.library@wur.nl 
Doctorate Studies

\title{
Effects of Digital Learning Materials on nursing students' mathematics learning, self-efficacy, and task value in vocational education
}

\author{
Diana P. Zwart ${ }^{\mathrm{a}, *}$, Omid Noroozi ${ }^{\mathrm{b}}$, Johannes E.H. Van Luit ${ }^{\mathrm{c}}$, Sui Lin Goei ${ }^{\mathrm{a}, \mathrm{d}}$, Arjen Nieuwenhuis ${ }^{\mathrm{e}}$ \\ ${ }^{\text {a }}$ Centre of Education and Movement Studies, Windesheim University of Applied Sciences, the Netherlands \\ ${ }^{\mathrm{b}}$ Education and Learning Sciences, Wageningen University and Research, the Netherlands \\ ${ }^{\mathrm{c}}$ Department of Special Needs Education, Utrecht University, the Netherlands \\ ${ }^{\mathrm{d}}$ LEARN! Research Institute, VU Amsterdam, the Netherlands \\ ${ }^{\text {e }}$ Senior secondary vocational education, Alfa College, the Netherlands
}

\section{A R T I C L E I N F O}

\section{Keywords:}

Digital learning materials (DLMs)

Nursing mathematics

Self-efficacy

Task value

\begin{abstract}
A B S T R A C T
The use of digital environments in nursing education offers new opportunities for nursing students' medical mathematics learning. The aim of this study was to investigate the effects of Digital Learning Materials (DLMs) on nursing students' mathematics learning, self-efficacy, and task value. A pre-test/post-test control group design was used. Students were assigned to the DLMs group (experimental condition) or the face-to-face group (control condition). Students in both conditions completed the same assignments and discussed these with their peers and the (online) teacher via the discussion board or in the classroom setting. The results showed that the mathematics learning of students undergoing DLMs training and of those undergoing face-to-face training improved from the pretest to the post-test, but no significant differences were found between the two conditions. A significant interaction effect between condition and self-efficacy was reported, producing a large reduction in the self-efficacy of students in the DLMs condition and a small reduction in the self-efficacy of students in the face-toface condition. No significant differences were found for students' task value. The study offers new insights for the future design of mathematics training with DLMs, focusing on students' appreciation of DLMs features, considering students with low and high learning abilities separately.
\end{abstract}

\section{Introduction}

Nurses are expected to have an accurate knowledge of how to administer medication, especially the mathematical knowledge needed for the safe calculation of medication dosages (Weeks et al., 2000, Weeks et al., 2013). Many training schemes and solutions have been invented to minimize errors in medication dosages; these include wearing a special 'do not disturb' smock while administering medication, or the mandatory 'check-double check' action (Actiz Health Organization, 2012). Although errors can occur at any stage from prescribing, dispensing and administering to recording and reporting, it is recognized that nurses are the final line of defence (Adhikari et al., 2014). Nurses' competencies in dose calculation are therefore of vital importance. These competencies are gained not only from the teaching of medical mathematics in the context of real life situations, but also from the teaching of ordinary computational skills, such as the addition, subtraction, multiplication and division of whole numbers, decimals and fractions, and conversions between decimals and fractions (Stelzer et al., 2019; Weeks et al., 2000). Not every student is aware of the procedural knowledge that contains the items of declarative knowledge needed when solving problems step-by-step (Anderson and Schunn, 2000; Ashcraft and Krause, 2007; Daubert and Ramani, 2019). In the long run, this procedural knowledge needs to be automatic so that it hardly needs any attention in future practice. So that nursing students do not lose track of the interconnections between regular computational and domain-specific medical mathematics skills, the teaching of these skills can be combined (Van Merriënboer and Kirschner, 2017). One approach to this is via Digital Learning Materials (DLMs).

DLMs offer possibilities for teaching mathematics that cannot be achieved by face-to-face delivery, such as place- and time-independent learning. Furthermore, DLMs offer more flexible and meaningful teaching by combining the teaching of regular and domain-specific medical mathematics with the support of instructional procedural and domain-specific clips, collaboration tools, and online guidance (Zwart

\footnotetext{
* Corresponding author.

E-mail addresses: dp.zwart@windesheim.nl (D.P. Zwart), omid.noroozi@wur.nl, o.noroozi@modares.ac.ir (O. Noroozi), J.E.H.vanLuit@uu.nl (J.E.H. Van Luit), sl.goei@windesheim.nl, s.l.goei@vu.nl (S.L. Goei), a.nieuwenhuis@alfa-college.nl (A. Nieuwenhuis).
} 
et al., 2017). Students can benefit from this support, because DLMs are retrievable at any time and wherever students are located. This also allows students to solve medical mathematics problems during traineeships. The instructional procedural clips clarify pieces of declarative knowledge, such as facts about ordinary computational skills, and connect these with domain-specific clips that demonstrate mathematical assignments with medical contexts. The literature suggests that the use of DLMs has positive effects on various aspects of students' learning, motivation, etc. (e.g. De Mooij et al., 2020; Mayer, 2014; Moreno, 2006; Passey et al., 2004). However, DLMs have not yet been used for nursing students' mathematics learning, or, in particular, for the teaching of both regular and medical mathematics skills in vocational education. This study, therefore, investigates the effectiveness of mathematics training with DLMs on nursing students' mathematics learning, task value and self-efficacy, comparing DLMs training with a traditional face-to-face method. Furthermore, students' appreciation of the various features of DLMs are investigated.

\section{Background}

\subsection{Domain-specific knowledge and working memory load}

Nursing students in senior secondary vocational education need to understand the clinical source of, and the relationship between, the elements of dosage and rate formulae and equations when solving calculation problems (Weeks et al., 2013a, p. e26). For this reason, the mathematical procedures must be identifiable: the students should learn cognitive and appropriate rules for developing the competencies necessary in complex care situations within their future jobs. Stelzer et al. (2019) refer to general and maths-specific conditions that foster mathematical conceptual knowledge. The domain-specific mathematical knowledge, defined by Alexander and Judy (1988) as declarative, procedural, and conditional knowledge, is the knowledge that nursing students must possess. To possess this knowledge, students need to memorize relevant information that can lead to action permitting the completion of specified tasks over indefinite periods of time (Tricot and Sweller, 2014. p. 266). As numbers become larger and more complex, the use of automatic or memorized knowledge decreases, thus increasing the load on the working memory (Ashcraft and Krause, 2007; Sweller, 2010).

Working memory is important for mathematical performance (Alloway et al., 2013; Daubert and Ramani, 2019; Wei et al., 2012). It is the capacity to store information over short periods (Baddeley, 1986). Peng et al. (2016, p. 466) acknowledge that: "When students are knowledgeable in a particular domain, they can encode and retrieve information specific to it more efficiently than when they are less knowledgeable". As such, working memory integrates domain-specific skills, knowledge and procedures to meet the particular demands of learning tasks within a specific domain. This implies that different mathematical skills may have different degrees of cognitive load.

\subsection{Cognitive load and students' learning abilities}

According to Sweller (2010), cognitive load in working memory comprises intrinsic, extraneous and germane cognitive load. Intrinsic cognitive load cannot be altered because it has to do with the expertise of the learner. Extraneous cognitive load refers to the extra load of irrelevant and mostly useless activities during learning, while germane cognitive load refers to the relevant and useful activities engaged in by a learner while interacting with learning materials (Kollar et al., 2014; Sweller, 2010). Variations in students' learning, however, require teachers to adapt education to the needs of their students (Corno, 2008). This also applies to DLMs, which can tailor students' learning experiences (De Mooij et al., 2020). A task within the reach of students with average achievement levels may be impossible for students with lower achievement levels while, on the other hand, students with high achievement levels will already have mastered the task. Therefore, instructional approaches with DLMs should consider the variations in students' learning, and decrease the extraneous load and increase the germane load for carrying out difficult tasks like mathematical calculations or solving complex problems (Noroozi et al., 2012). To increase the germane load, instructional procedural knowledge clips and domain-specific knowledge clips with procedures, text and pictures from real life contexts can be used to teach mathematics. The instructional design with DLMs should align these instructional procedural knowledge clips to the domain-specific clips, making it possible to lower the extraneous cognitive load and increase the germane cognitive load (Kollar et al., 2014).

\subsection{Instructional design with DLMs}

DLMs offer educational opportunities that cannot be obtained through regular face-to-face forms of learning and instruction (Kalyuga and Liu, 2015). DLMs can increase the effectiveness of instruction and offer a more diversified learning experience without the constraints of time and space (Chen, 2011; Lee and Hung, 2015; Noroozi et al., 2013). Despite this advantage, Zwart et al. (2017) acknowledge that the role of teachers is not to be underestimated. Teachers encounter technologyrelated problems when supporting students' participation and collaboration online (Compton, 2009). These problems relate to the teachers' abilities to use software and hardware, and their communication skills for motivating students online and forging a group identity in the online community (Gray, 2004). DLMs with an online teacher can enhance the positive effects on perceived learning, but students and teachers are not always motivated to use DLMs for instructional practice (Wu et al., 2010). This is a striking point, since motivation is an important condition for engaging in learning processes in any educational context. Motivation is the internal state that initiates, maintains and energizes the learner's effort to engage in a learning process (Mayer, 2014, p. 171). Therefore, as with face-to-face learning, both teachers and students need to be motivated to generate a positive learning atmosphere within the DLMs context. One aspect that needs to be taken into account from motivational view when using DLMs is the self-efficacy of students (Huang, 2012).

\subsection{Self-efficacy}

Self-efficacy refers to the confidence of a learner when completing a task successfully (Bandura, 1986). Self-efficacy is correlated with academic achievement: Students feel more competent when they do well and value their tasks highly (Denissen et al., 2007; Reichwein Zientek et al., 2019). Self-efficacy can be enhanced by creating a learning environment that allows for collaboration and autonomy (Pekrun, 2006). In this context, care should be taken to ensure that the learning environment does not make too many demands on learners, as this might give rise to negative emotions. Wu et al. (2010) designate self-efficacy in e-learning environments as "computer self-efficacy" (p. 157). They state that computer self-efficacy influences performance expectations, which may, in turn, influence behaviour. This implies that students will be more motivated to learn and will benefit and learn more with DLMs when they become more confident and capable of learning with DLMs and more accustomed to doing so. Passey et al. (2004) found that DLMs had a motivational impact on engagement, but little research has been conducted on the motivational aspects of learning and DLMs: this has largely been neglected (Leutner, 2014; Mayer, 2014). Apart from selfefficacy in DLMs, appreciation of a task, or task value, also influences learning behaviour and academic results (Joo et al., 2013; Wigfield and Eccles, 2000).

\subsection{Task value}

Task value is a concept that indicates the importance, usefulness or 
interest a student ascribes to a certain task (Wigfield and Eccles, 2000). Motivational effort depends on the importance the student ascribes to completing the task. Andrews and Aikens (2019) report that students who gave a high utility task value to mathematics in the context of biology were more interested in using mathematics to understand biology. Van der Veen and Peetsma (2009) show that students ascribing a high task value to a task were more motivated than students giving it a low task value. Joo et al. (2013) state that task value is a predictor of student satisfaction with the task. Denissen et al. (2007) found that task value is positively related to perceived competence. There is no empirical scientific literature on how DLMs will impact task value and selfefficacy. Affective aspects, such as motivation and emotion, have largely been neglected in research on online environments such as DLMs (Leutner, 2014; Mayer, 2014). Therefore, this study aims to explore the effects of DLMs on learning outcomes, self-efficacy, and task value in nursing mathematics in secondary vocational education.

\subsection{The objectives and research questions}

This study aims to investigate the effects on learning outcomes, selfefficacy, and task value of solving medical mathematics problems with DLMs training. A pre-test/post-test control group design was used. Students were assigned to the DLMs training group (experimental condition) or the face-to-face training group (control condition). Furthermore, this study explores the differences between students with high and low learning abilities, and what they appreciate about the DLMs features. The following research questions are formulated to address these issues:

1. What are the differences between DLMs training and face-to-face training in relation to the mathematics learning of nursing students in vocational education?

2. What are the differences between DLMs training and face-to-face training in relation to nursing students' self-efficacy in vocational education?

3. What are the differences between DLMs training and face-to-face training in relation to nursing students' task value in vocational education?

4. What are the differences between students with high learning abilities (highest 25\%) and students with low learning abilities (lowest $25 \%$ ) in relation to their appreciation of the features of DLMs?

\section{Method}

\subsection{Context and participants}

This study took place at a regional senior secondary vocational education school in the Netherlands. Senior secondary vocational education comprises programmes on four qualification levels, ranging from level 1 to level 4 of the European Qualification Framework (Baartman and De Bruijn, 2011, p. 126). Students obtain a qualification by learning in school and in the workplace. Students with a level 4 qualification can enter Bachelor's programmes in higher professional education. In this study, the focus is on the learning of level 4 students. The participants were first-year nursing students $(\mathrm{N}=39)$. Nursing students are challenged to achieve an adequate level in two separate courses: mathematics and specific medical mathematics. These two complementary subjects are required to accomplish the learning task in this study successfully. The students were divided into two groups: the experimental group (DLMs condition) and the control group (face-toface condition). The DLMs condition consisted of 28 students who attended Monday mathematics lessons. The face-to-face condition consisted of 11 students who attended Wednesday mathematics lessons. Only these classes were available because of central timetabling, which explains the discrepancy in the numbers of students. All the participants were female. The mean age was $18.8(S D=2.93)$ for the students in the
DLMs condition and $18.5(S D=3.59)$ for the students in the face-toface condition. Although the students in the face-to-face condition ( $M=50.70, S D=3.58$ ) generally scored higher than the students in the DLMs condition $(M=48.00, S D=4.16)$ in terms of their learning abilities, this difference was not significant: $t(37)=-1.91, p=.05$. The teacher was the same for both conditions: he was male, aged 37, with a Master's in mathematics for senior secondary vocational education and five years of professional experience in this education sector.

\subsection{Materials and learning tasks}

The mathematics topic was measurement and geometry. Measurement relates to the control of real things, finding answers to questions like how big or heavy something is or how long something lasts. Geometry involves problem-solving and reasoning about shape, size, the relative position of figures, and the properties of space (see Peng et al., 2016, p. 458). Students in both the DLMs condition and the face-to-face condition were offered the same learning activities and mathematics assignments.

\subsection{Digital learning materials (DLMs)}

DLMs were designed and used in this study on a web-enabled platform (Wikispaces) and consisted of the following features: structured content, goals, assignments, procedural knowledge clips, instructional domain-specific clips, and a discussion board. The focus of the learning content with DLMs was structured for each week. Instructional procedural knowledge clips and domain-specific clips were present, so that there could be a focus on the relationships between the mathematical elements (see Fig. 1). There was a discussion board for students to work together and ask questions about the mathematics assignments prescribed by the teacher. For more detail, see Zwart et al. (2017).

\subsection{Procedure and measurements}

Overall, the experimental session consisted of four main phases (see Table 1). During (1) the introduction and personal data phase, which took $45 \mathrm{~min}$, students read the introduction letter about the ethical aspects of research study for $5 \mathrm{~min}$. Then the teacher explained the procedure, materials, and the purpose of the research study for about $30 \mathrm{~min}$. They were then asked to complete a questionnaire on their personal data (10 min). During (2) the individual pre-test measurements phase (in total $95 \mathrm{~min}$ ), students first received an introductory explanation of how to answer different questions of various surveys on self-efficacy, task-value, domain-specific mathematical knowledge, and the non-verbal abilities test $(5 \mathrm{~min})$. Students were then given $15 \mathrm{~min}$ to fill in the surveys on self-efficacy and task-value. After a 10-min break, they were tested on their domain-specific mathematical knowledge (30 min) followed by the non-verbal abilities test which took $45 \mathrm{~min}$. Then (3) the learning phase began. This phase for both conditions took about $60 \mathrm{~min}$ for six consecutive weeks. The method of delivery was the only difference between the two conditions. During (4) the post-tests and debriefing phase $(60 \mathrm{~min})$, students were first tested on their domain-specific mathematical knowledge $(30 \mathrm{~min}$ ) followed by a $15 \mathrm{~min}$ assessment on their self-efficacy and task-value measurements. As an extra activity, students in the DLMs condition were also asked to fill in a survey on their satisfaction with the use of DLMs and their learning experiences and outcomes (10 min). Finally, students received a short debriefing for about $5 \mathrm{~min}$.

\subsubsection{Method of delivery via face-to-face classes}

Students in the face-to-face condition were taught face-to-face mathematics lessons as usual in the classroom for $1 \mathrm{~h}$ a week for six consecutive weeks. The teacher was present in all sessions and students could ask questions in a regular manner when solving mathematical 


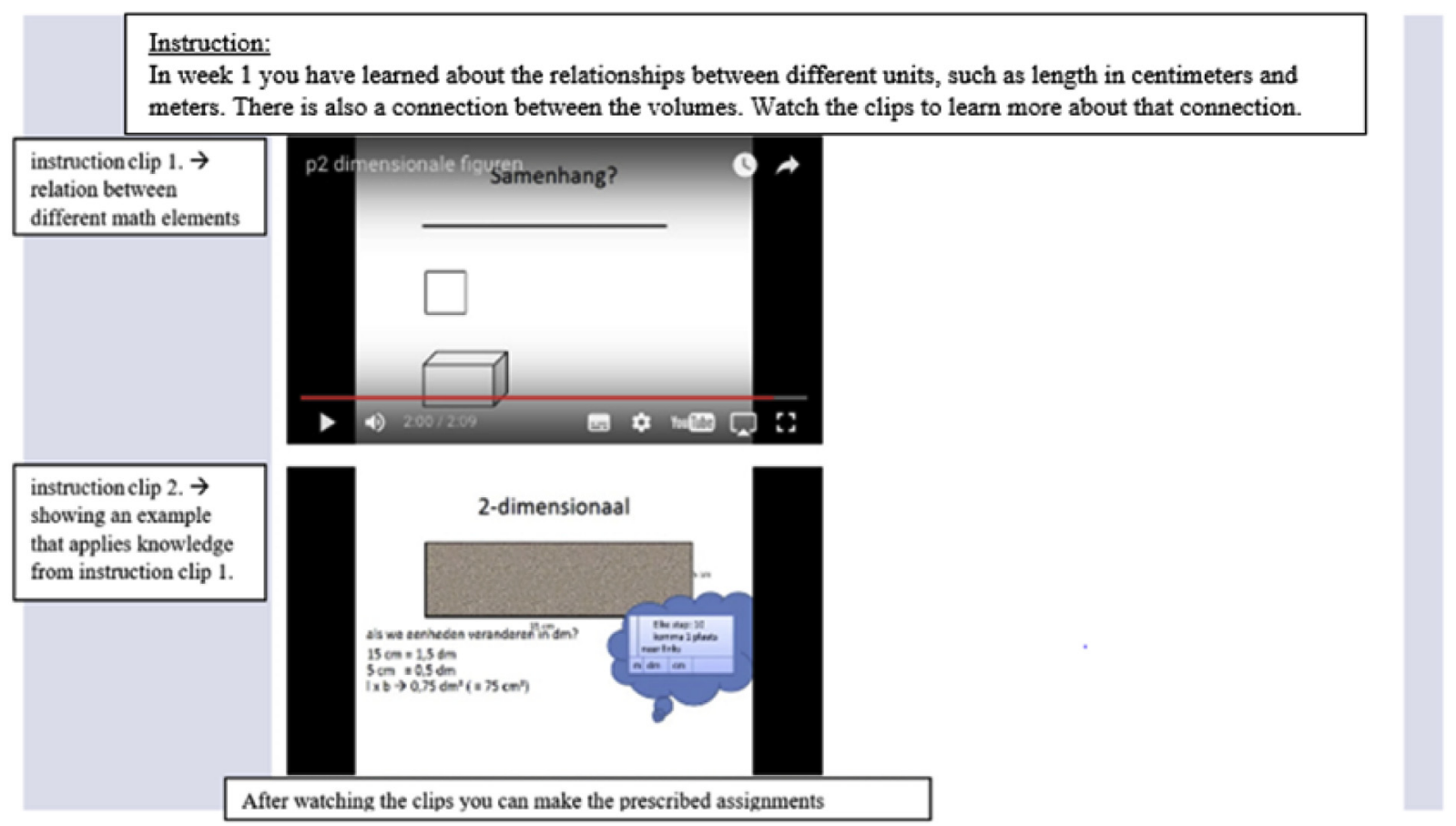

Fig. 1. Instructional clips that demonstrate the relationship between mathematical elements.

problems. Teacher delivered instruction as usual when needed and students had the opportunity to interact with their fellow students and the teacher.

\subsubsection{Method of delivery via DLMs}

Students in the DLMs condition were taught with DLMs for $1 \mathrm{~h}$ a week for six consecutive weeks. In this condition, students carried out assignments, watched instructional clips, and collaborated online with other students and their online teacher when solving mathematical problems. In this condition, an online teacher was available to answer any question related to the mathematical problems or the functionalities of the DLMs.

\subsubsection{Measurement of students' learning outcomes}

The students took a standardized mathematics test (Startrekenen, Lagendijk et al., 2013). The test consisted of tasks with text and pictures about domain-specific knowledge of geometry. Students could score a maximum of 37 points on the test. The test is validated and used as a school-based formative assessment.

\subsubsection{Measurement of students' learning abilities}

The Raven test was used to measure students' level of general nonverbal intelligence; this test takes into account both innate factors and acquired skills (Alloway and Alloway, 2010; Raven et al., 1992). Lovett and Forbus (2017) state that the Raven test is the best predictor of fluid intelligence and a good predictor of mathematical ability. The test consists of 60 items divided into five sets of 12 items each, ranging from easy to complex (subtests: A, B, C, D, and E). Each item consists of a figure with a missing piece. Below the figure, there are six or eight answers that might be the missing piece. Only one answer is correct. The reliability score of the test in this study was average (Cronbach's $\alpha$ $=.60)$. The test was handed out on paper. There was no time limit on the test; completing the test in this study took between 45 and $60 \mathrm{~min}$.

Table 1

Overview of the Procedure of the Study for both DLMs and Face-to-Face Conditions.

\begin{tabular}{|c|c|c|}
\hline Procedure in the DLMs condition & Procedure in the face-to-face condition & Duration \\
\hline 1) Introduction and personal data & Introduction and personal data & $45 \mathrm{~min}$ \\
\hline Reading introduction letter about the ethical aspects of research study & $\begin{array}{l}\text { Reading introduction letter about the ethical aspects of } \\
\text { research study }\end{array}$ & $5 \min$ \\
\hline $\begin{array}{l}\text { Introductory explanations about the procedure, materials, and the purpose of the } \\
\text { research study }\end{array}$ & $\begin{array}{l}\text { Introductory explanations about the procedure of the } \\
\text { research study }\end{array}$ & $30 \mathrm{~min}$ \\
\hline Assessment of personal data & Assessment of personal data & $10 \mathrm{~min}$ \\
\hline 2) Individual pre-test measurements & Individual pre-test measurements & $95 \mathrm{~min}$ \\
\hline Introductory remarks & Introductory remarks & $5 \mathrm{~min}$ \\
\hline Assessment of self-efficacy and task-value & Assessment of self-efficacy and task-value & $15 \mathrm{~min}$ \\
\hline Pre-test assessment of domain-specific mathematical knowledge & $\begin{array}{l}\text { Pre-test assessment of domain-specific mathematical } \\
\text { knowledge }\end{array}$ & $30 \mathrm{~min}$ \\
\hline Individual non-verbal abilities test & Individual non-verbal abilities test & $45 \mathrm{~min}$ \\
\hline 3) Learning phase through DLMs & Learning phase through face-to-face & 60 min per week for six weeks \\
\hline 4) Post-tests and debriefing & Post-tests and debriefing & $60 \min$ \\
\hline Post-test assessment of domain-specific mathematical knowledge & $\begin{array}{l}\text { Post-test assessment of domain-specific mathematical } \\
\text { knowledge }\end{array}$ & $30 \mathrm{~min}$ \\
\hline Assessment of self-efficacy and task-value & Assessment of self-efficacy and task-value & $15 \mathrm{~min}$ \\
\hline Assessment of satisfaction with the DLMs & - & $10 \mathrm{~min}$ \\
\hline Debriefing & Debriefing & $5 \mathrm{~min}$ \\
\hline
\end{tabular}




\subsubsection{Measurement of students' self-efficacy and task value}

The students' self-efficacy and task value were measured using the Global Math Motivation Questionnaire for Children (Prast et al., 2018). The questionnaire was adjusted for secondary vocational education students. Cronbach's alpha for the 15 items of this questionnaire was .78. Although this can be considered adequate, a closer examination of the total statistics for the questionnaire items indicated that the alpha would increase to .84 if item 2 were removed. This item asked students to rate the following sentence: "I make many mistakes in mathematics". Consequently, this item was removed from the questionnaire, and all subsequent analyses were based on the remaining 14 items. Finally, the Cronbach's alphas (with item 2 deleted) were .88 for self-efficacy and .78 for task value. The answers were given on a four-point Likert scale. High scores meant that working with DLMs fostered students' self-efficacy and that students appreciated the task with DLMs (task value).

\subsubsection{Measurement of students' appreciation of the features of DLMs}

We set up a questionnaire for students in the experimental condition with items reflecting their appreciation of the features of DLMs: the structure of the website (e.g. general expectations), the goals, the procedural knowledge clips, the domain-specific clips, the assignments, and the discussion board. This questionnaire consisted of 45 items with a five-point Likert scale ranging from fully disagree to fully agree. The reliability measurement for this questionnaire was high (Cronbach's $\alpha$ $=.96)$.

\subsection{Analyses}

A mixed ANOVA for repeated measurement was conducted to determine the changes from pre-test to post-test and to see if there were any differences between the scores of the nursing students in the DLMs and face-to-face conditions in terms of learning mathematics and selfefficacy. An ANOVA was conducted to compare the mean differences between students in the two conditions in terms of task value. Furthermore, for students in the DLMs condition, we divided the students' learning abilities $(M=48.00, S D=4.16$, Min $=39.00$, $\operatorname{Max}=55.00)$ into the lowest $25 \%$ of scores $(M=43.10, S D=2.47)$ and the highest $25 \%$ of scores $(M=52.50, S D=1.60)$, and conducted an ANOVA to test whether the appreciation of the DLMs features was different for these groups.

\subsection{Ethics}

The Faculty Ethics Review Committee (FETC) of the Faculty of Social Sciences of Utrecht University reviewed and approved this research study with respect to ethical implications which was registered under the number 19-230. The FETC promotes, monitors, and tests ethical conduct in scientific research. This committee assumes that research at the Faculty of Social Sciences of Utrecht University is carried out in an ethically responsible manner, following the applicable codes of conduct and professional codes and (European, national, and international) legislation and regulations. To comply with the ethical aspects, two weeks before the intervention, students received a letter in which they were informed that the results of this study will be used for research purposes. With this letter, students were given the opportunity to decline to participate in this research study. No student declined to participate in the research study. Students were assured that identifying information was not available to anyone, except for researchers. Results were de-identified by numbering the students and their test results both in the pre-tests and in the post-tests. This implies that student's data and results were treated confidentially meaning that no one could link the results to any individual student.

\section{Results}

\subsection{Results for students' mathematics learning outcomes}

The average scores for the nursing students' mathematics learning outcomes improved significantly in both the DLMs condition $\left(M_{\mathrm{T} 1}=\right.$ 19.12, $\left.S D_{\mathrm{T} 1}=8.82 ; M_{\mathrm{T} 2}=26.15, S D_{\mathrm{T} 2}=7.99\right)$ and the face-to-face condition $\left(M_{\mathrm{T} 1}=17.70, S D_{\mathrm{T} 1}=7.12 ; M_{\mathrm{T} 2}=27.80, S D_{\mathrm{T} 2}=7.61\right)$ from pre-test to post-test, $F(1,34)=42.83, p<.001, \eta 2=.56$. No significant difference was found between the two conditions, $F(1$, 34) $=33.85, p=.25$.

\subsection{Results for students' self-efficacy outcomes}

A significant main effect was obtained regarding the students' selfefficacy scores $F(1,36)=16.56, p<.001, \eta 2=.32$. The average scores of the nursing students' self-efficacy decreased from the pre-test $(M=12.03, S D=2.97)$ to the post-test $(M=13.42, S D=2.34)$. There was no significant difference between the two conditions, $F(1$, $36)=3.56, p=.07$. However, a significant interaction between condition and self-efficacy was reported, $F(1,36)=7.35, p<.05, \eta 2=$ .17. Examination of the means indicated that the intervention produced a large reduction in the self-efficacy of nursing students in the DLMs condition from pre-test $(M=13.15, S D=2.54)$ to post-test ( $M=11.33, S D=3.09$ ), and a small reduction in the self-efficacy of nursing students in the face-to-face condition from pre-test ( $M=14.09$, $S D=1.70)$ to post-test $(M=13.73, S D=1.85)$.

\subsection{Results for students' task value outcomes}

No significant main effect was obtained for the results for task value, $F(1,36)=1.15, p<.29$. The results for task value were almost equal in the pre-test $(M=20.45, S D=3.78)$ and the post-test $(M=20.03$, $S D=3.66)$. No significant differences were found between the two conditions, $F(1,36)=.36, p=.74$.

\subsection{Differences in appreciation of DLMs between students with high and low learning abilities}

Students in the low and high learning ability groups differed in their appreciation of the DLMs features (see Table 2). The DLMs feature 'domain-specific clips' obtained a statistically significant result: students with high learning abilities appreciated the domain-specific instructional clips significantly more than students with lower learning abilities: $F(1,15)=6.44, p=.02, \eta 2=.30$. For the remainder of the DLMs features, no significant differences were found: structure $F(1,15)$ $=.67, p=.43, \eta 2=.04$; goals $F(1,15)=.64, p=.44, \eta 2=.04$; procedural knowledge clips $F(1,15)=3.59, p=.08, \eta 2=.19$; assignments $F(1,15)=1.24, p=.28, \eta 2=.08$; and discussion board $F$ $(1,15)=.97, p=.34, \eta 2=.06$.

\section{Discussion}

The present study investigated the effects of DLMs teaching on mathematics learning outcomes, self-efficacy, and task value for firstyear nursing students in vocational education, with a pre-test/post-test control group design. Students were assigned to the DLMs training group (experimental condition) or the face-to-face training group (control condition). The appreciation of DLMs features by students with low and high learning abilities was compared as well.

With regard to the first research question, we can conclude that both the DLMs training and the face-to-face training conditions enhanced nursing students' mathematics learning. Nursing students' understanding of the relationship between the different mathematical elements necessary for doing calculations in medical situations was especially emphasized in the DLMs training via the instructional clips; the 
Table 2

Nursing students' Raven scores, mathematics test scores and scores for appreciation of DLMs features.

\begin{tabular}{|c|c|c|c|c|c|c|c|c|c|c|c|c|}
\hline \multirow[t]{3}{*}{ Measure } & \multicolumn{4}{|c|}{ Total experimental group } & \multicolumn{4}{|c|}{ Group with lowest $25 \%$} & \multicolumn{4}{|c|}{ Group with highest $25 \%$} \\
\hline & \multicolumn{4}{|c|}{$\mathrm{N}=27$} & \multicolumn{4}{|c|}{$\mathrm{N}=9$} & \multicolumn{4}{|c|}{$\mathrm{N}=8$} \\
\hline & M & $\mathrm{SD}$ & Min & Max & M & $\mathrm{SD}$ & Min & Max & M & SD & Min & $\operatorname{Max}$ \\
\hline Raven & 48.0 & 4.2 & 39.0 & 55.0 & 43.1 & 2.5 & 39.0 & 46.0 & 52.5 & 1.6 & 51.0 & 55.0 \\
\hline Pre-test & 18.8 & 8.8 & 3.0 & 36.0 & 17.8 & 9.6 & 3.0 & 29.0 & 20.9 & 7.0 & 11.0 & 34.0 \\
\hline Post-test & $25.8^{*}$ & 8.0 & 13.0 & 38.0 & 26.4 & 9.3 & 13.0 & 38.0 & 27.1 & 7.6 & 15.0 & 38.0 \\
\hline Structure & 33.3 & 9.8 & 15.0 & 49.0 & 32.4 & 9.6 & 15.0 & 46.0 & 36.0 & 8.1 & 25.0 & 49.0 \\
\hline Goals & 12.3 & 3.1 & 4.0 & 17.0 & 11.9 & 3.6 & 4.0 & 16.0 & 13.0 & 1.6 & 11.0 & 15.0 \\
\hline Clips Procedural & 18.1 & 4.8 & 8.0 & 27.0 & 15.6 & 4.1 & 8.0 & 20.0 & 19.3 & 3.9 & 14.0 & 26.0 \\
\hline Clips Domain-Spec & 23.6 & 6.9 & 8.0 & 35.0 & $20.2^{*}$ & 6.3 & 10.0 & 31.0 & $26.9^{*}$ & 4.1 & 23.0 & 35.0 \\
\hline Assignments & 27.5 & 4.7 & 15.0 & 36.0 & 25.9 & 4.5 & 15.0 & 30.0 & 28.4 & 4.7 & 22.0 & 36.0 \\
\hline Discussion Board & 17.6 & 4.5 & 10.0 & 25.0 & 16.9 & 4.7 & 10.0 & 24.0 & 19.3 & 4.5 & 10.0 & 25.0 \\
\hline
\end{tabular}

${ }^{*} p<.05$.

procedural knowledge clips clarified facts from ordinary computational skills and connected them with the assignments in the instructional domain-specific clips. Since these instructional clips were retrievable at any time and in any location, nursing students were able to watch these demonstrations on how to apply procedures to mathematical problems over and over again. As a result, it was expected that nursing students from the DLMs training would be more capable of making connections between ordinary computational and domain-specific skills, and thus would be more likely to improve their mathematics learning, than nursing students from the face-to-face training who received their instruction only once a week in a classroom setting (Chen, 2011; Lee and Hung, 2015; Noroozi et al., 2013; Zwart et al., 2017). In contrast to these expectations, no significant difference was found between the two conditions. However, we should bear in mind that students in the faceto-face condition ( $M=50.7, S D=3.58$ ) tended to have higher scores for their learning abilities than students in the DLMs condition $(M=48.0, S D=4.16)$.

Concerning research question two, we found that students' self-efficacy decreased after the intervention. Pekrun (2006) states that learning environments that allow for collaboration and autonomy enhance self-efficacy. That might be the case in classroom settings, but in this study the online DLMs training showed the opposite effect. According to social cognitive theory (Wu et al., 2010, p. 157):

Individuals form their perceptions of self-efficacy towards a task based on cue they receive from four information sources: (1) by past experience and familiarity with similar activities, (2) through vicarious learning, (3) with social support and encouragement, and (4) through attitude toward the task.

One plausible explanation for the decrease in students' self-efficacy is that the learning environment with DLMs demanded too much from these nursing students, since it was their first online education experience and they were not familiar with the instructional activities in the DLMs training. Online education requires self-directed learning from the individual student and also online interaction with other peers and the online teacher. This shared regulation of interaction and collaboration needs task conditions such as quality criteria or criteria for the completion of tasks (Hadwin et al., 2011). These conditions were not clearly communicated beforehand. Perhaps the DLMs features demanded too much from the nursing students and thus gave rise to negative emotions (Pekrun, 2006).

With regard to the third research question, in contrast to several previous studies (e.g. Andrews and Aikens, 2019; Denissen et al., 2007; Joo et al., 2013; Van der Veen and Peetsma, 2009; Wigfield and Eccles, 2000), the students' task value scores showed no significant difference between the DLMs training group and the face-to-face training group. Again, it should be noted that this was the first attempt by these students to work with DLMs in a real educational setting. Students will be more motivated to learn, and will benefit more and learn more, when they become more confident and capable of learning with DLMs and more accustomed to doing so (Wu et al., 2010). For this reason, teachers' online communication skills to motivate students for mathematics tasks with DLMs should not be underestimated (Gray, 2004; Zwart et al., 2017).

With regard to the fourth research question, the results showed that the students with higher learning abilities, based on the Raven test, appreciated the instructional domain-specific clips DLMs feature more than students with lower learning abilities. Moreover, we discovered that 19 per cent of all the variability in the differences in the appreciation of DLMs features by students with high and low learning abilities was explained by the DLMs feature of instructional procedural knowledge clips. It seems that students with low learning abilities find it more difficult to engage when they are interacting with learning materials, which increases their extraneous load and thus their working memory load (Kollar et al., 2014; Sweller, 2010). In educational classroom settings, students rely heavily on their teacher's affirmations, and consequently do not build their own starting points for evaluation (Baldwin, 1967). Since these affirmations are related to the teacher, his proximity and attention is, in itself, confirmatory for students. Students' dependence can lead to fear if the teacher is absent. As a consequence, students find it difficult to break through their own learning and studying patterns in relation to their expectations of both their teacher and the other students.

\section{Conclusion}

Overall, this study showed that nursing students became less confident during a period of learning with DLMs, although their confidence did not affect their mathematics learning. If we want to create more flexible learning activities with DLMs that engage nursing students and encourage them to participate actively in DLMs training for present and future (lifelong) learning, certain aspects should be taken into account. First, starting points should be provided to students that enable them to support their own online evaluation. Secondly, there should be task conditions that are discussed beforehand and that describe the quality criteria for assignments or criteria for completion of tasks. Thirdly, the teacher and the students should not only discuss the assignments, but should also share rules and come to an agreement on online collaboration and online interaction. Finally, the teacher's online role should not only encourage feedback for finishing assignments but also support students socially for their sense of efficacy. Another point that can enhance computer self-efficacy is to move DLMs forward to a more virtual-based learning environment. According to Xinhao and Fengfeng (2016) virtual-based learning can foster affective, behavioural and cognitive engagement. Many problem-solving scenarios can be designed that enable active interactions with the content and enhance knowledge acquisition and transfer. 


\subsection{Limitations}

This study had a small sample of participants, especially in the control group. This might limit the generalizability of the findings of the study and might lead to strong claims that are based only on coincidence. This would imply that the findings of this study should be treated cautiously. We did not control for the various nursing students' needs or the communication skills of the teacher in motivating the students online. Furthermore, we did not count for the actual level of engagement especially for the students in the DLMs condition. For example, we did not collect information on the extent to which students used various features of the DLMs, and the number of clicks on these features. Replication of this study with more nursing students and measuring their levels of engagement by checking their activities in the DLMs would be needed to confirm the results of this study. Therefore, a future study should also target second- and third-year nursing students to see to what extent similar or different results are obtained.

\section{CRediT authorship contribution statement}

Diana P. Zwart: Conceptualization, Methodology, Validation, Data curation, Formal analysis, Investigation, Resources, Writing - original draft, Visualization. Omid Noroozi: Validation, Writing - review \& editing, Supervision. Johannes E.H. Van Luit: Validation. Sui Lin Goei: Validation, Writing - review \& editing, Supervision.

\section{Appendix A. Supplementary data}

Supplementary data to this article can be found online at https:// doi.org/10.1016/j.nepr.2020.102755.

\section{References}

Adhikari, R., Tocher, J., Smith, P., Corcoran, J., MacArthur, J., 2014. A multi-disciplinary approach to medication safety and the implication for nursing education and practice. Nurse Educ. Today 34, 185-190. https://doi.org/10.1016/j.nedt.2013.10.008.

Actiz Health Organization, 2012. Veilige principes in de medicatieketen [Safety principles in chain of medication]. https://www.zorgvoorbeter.nl/docs/PVZ/vindplaats/ medicatieveiligheid/veilige-principes-in-de-medicatieketen.pdf.

Alexander, P.A., Judy, J.E., 1988. The interaction of domain-specific and strategic knowledge in academic performance. Rev. Educ. Res. 58, 375-404.

Alloway, T.P., Alloway, R.G., 2010. Investigating the predictive roles of working memory and IQ in academic attainment. J. Exp. Child Psychol. 106, 20-29. https://doi.org/ 10.1016/j.jecp.2009.11.003.

Alloway, T.P., Bibile, V., Lau, G., 2013. Computerized working memory training: can it lead to gains in cognitive skills in students? Comput. Hum. Behav. 29, 632-638. https://doi.org/10.1016/j.chb.2012.10.023.

Anderson, J.R., Schunn, C.D., 2000. Implications of the ACT-R learning theory: No magic bullets. In: Glaser, R. (Ed.), Advances in Instructional Psychology, Vol. 5, Educational Design and Cognitive Science. Lawrence Erlbaum, Mahwah, New Jersey, pp. 1-33.

Andrews, S.E., Aikens, M.L., 2019. Life science majors' math-biology task values relate to student characteristics and predict the likelihood of taking quantitative biology courses. J. Microbiol. Biol. Educ. 19, 1-10. https://doi.org/10.1128/jmbe.v19i2. 1589.

Ashcraft, M.H., Krause, J.A., 2007. Working memory, math performance, and math anxiety. Psychon. Bull. Rev. 14, 243-248. https://doi.org/10.3758/BF03194059.

Baartman, L.K.J., De Bruijn, E., 2011. Integrating knowledge, skills, and attitudes: conceptualising learning processes towards vocational competence. Educ. Res. Rev. 6 , 125-134. https://doi.org/10.1016/j.edurev.2011.03.001.

Baddeley, A.D., 1986. Working Memory. Oxford University Press, New York. Baldwin, A.L., 1967. Theories of Child Development. John Wiley and Sons, New York.

Bandura, A., 1986. Social Foundations of Thought and Action: A Social Cognitive Theory. Prentice-Hall, Englewood Cliffs, NJ.

Chen, J.-L., 2011. The effects of education compatibility and technological expectancy on e-learning acceptance. Comput. Educ. 57, 1501-1511. https://doi.org/10.1016/j. compedu.2011.02.009.

Compton, L.K.L., 2009. Preparing language teachers to teach language online: a look at skills, roles, and responsibilities. Comput. Assist. Lang. Learn. 22, 73-99. https://doi. org/10.1080/09588220802613831.

Corno, L., 2008. On teaching adaptively. Educ. Psychol. 43, 161-173. https://doi.org/10. $1080 / 00461520802178466$.

Daubert, E.N., Ramani, G.B., 2019. Math and memory in bilingual preschoolers: the relations between bilingualism, working memory, and numerical knowledge. J. Cognit. Dev. 20, 314-333. https://doi.org/10.1080/15248372.2019.1565536.

De Mooij, S.M.M., Kirkham, N.Z., Raijmakers, M.E.J., Van der Maas, H.L.J., Dumontheil,
I., 2020. Should online math learning environments be tailored to individuals' cognitive profiles? J. Exp. Child Psychol. 191, 1-15. https://doi.org/10.1016/j.jecp. 2019.104730.

Denissen, J.J.A., Zarrett, N.R., Eccles, J.S., 2007. I like to do it, I'm able, and I know I am: longitudinal couplings between domain-specific achievement, self-concept, and interest. Child Dev. 78, 430-437. https://doi.org/10.1111/j.1467-8624.2007.01007x.

Gray, B., 2004. Informal learning in an online community of practice. J. Distance Educ. $19,20-35$.

Hadwin, A.F., Järvelä, S., Miller, M., 2011. Self-regulated, co-regulated, and socially shared regulation of learning. In: Zimmerman, B.J., Schunk, D.H. (Eds.), Handbook of Self-Regulation of Learning and Performance. Routledge, New York, pp. 65-84.

Huang, C., 2012. Discriminant and incremental validity of self-concept and academic selfefficacy: a meta-analysis. Educ. Psychol. 32, 777-805. https://doi.org/10.1080/ 01443410.2012 .732386$.

Joo, Y.J., Lim, K.Y., Kim, J., 2013. Locus of control, self-efficacy, and task value as predictors of learning outcome in an online university context. Comput. Educ. 62 , 149-158. https://doi.org/10.1016/j.compedu.2012.10.027.

Kalyuga, S., Liu, T.C., 2015. Guest editorial: managing cognitive load in technology-based learning environments. Educ. Technol. Soc. 18 (4), 1-8. http://www.jstor.org/ stable/jeductechsoci.18.4.1.

Kollar, I., Ufer, S., Reichersdorfer, E., Vogel, F., Fischer, F., Reiss, K., 2014. Effects of collaboration scripts and heuristic worked examples on the acquisition of mathematical argumentation skills of teacher students with different levels of prior achievement. Learn. InStruct. 32, 22-36. https://doi.org/10.1016/j.learninstruc. 2014.01.003.

Lagendijk, R., Schaap, K., De Wit, P., Kramer, M., Lugten, I., Wolters, S., Kluiters, C., Van Abswoude, J., Folkertsma, J., Wynia, R., 2013. Startrekenen [Starting Mathematics]. Deviant, Amersfoort, The Netherlands.

Lee, L.-T., Hung, J.C., 2015. Effects of blended e-learning: a case-study in higher education tax learning setting. Human-centric Comput. Inf. Sci. 5, 1-15. https://doi.org/ 10.1186/s13673-015-0024-3.

Leutner, D., 2014. Motivation and emotion as mediators in multimedia learning. Learn. InStruct. 29, 174-175. https://doi.org/10.1016/j.learninstruc.2013.05.004.

Lovett, A., Forbus, K., 2017. Modeling visual problem solving as analogical reasoning. Psychol. Rev. 124, 60-90. https://doi.org/10.1037/rev0000039.

Mayer, R.E., 2014. Incorporating motivational learning into multimedia learning. Learn. InStruct. 29, 171-173. https://doi.org/10.1016/j.learninstruc.2013.04.003.

Moreno, R., 2006. Does the modality principle hold for different media? A test of the method-affects-learning hypothesis. J. Comput. Assist. Learn. 22, e149-e158. https:// doi.org/10.1111/j.1365-2729.2006.00170.x.

Noroozi, O., Biemans, H.J.A., Weinberger, A., Mulder, M., Chizari, M., 2013. Scripting for construction of a transactive memory system in multidisciplinary CSCL environments. Learn. InStruct. 25, 1-12. https://doi.org/10.1016/j.learninstruc.2012.10. 002 .

Noroozi, O., Busstra, M.C., Mulder, M., Biemans, H.J.A., Tobi, H., Geelen, M.M.E.E., Van 't Veer, P., Chizari, M., 2012. Online discussion compensates for suboptimal timing of supportive information presentation in a digitally supported learning environment. Educ. Technol. Res. Dev. 60, 193-221. https://doi.org/10.1007/s11423-011-9217-2.

Passey, D., Goodison, R., Machell, J., McHugh, G., 2004. The Motivational Effect of ICT on Pupils. Lancaster University, Department of Educational Research. http:// downloads01.smarttech.com/media/research/international_research/uk/lancaster report.pdf.

Pekrun, R., 2006. The control-value theory of achievement emotions: assumptions, corollaries, and implications for educational research and practice. Educ. Psychol. Rev. 18 (4), 315-341. https://doi.org/10.1007/s10648-006.

Peng, P., Namkung, J., Barnes, M., Sun, C., 2016. A meta-analysis of mathematics and working memory: moderating effects of working memory domain, type of mathematics skill, and sample characteristics. J. Educ. Psychol. 108, 455-473. https://doi. org/10.1037/edu0000079.

Prast, E.J., van de Weijer, E., Miocevic, M., Kroesbergen, E.H., Van Luit, J.E.H., 2018. Relations between mathematics achievement and motivation in students of diverse achievement levels. Contemp. Educ. Psychol. 55, 84-96. https://doi.org/10.1016/j. cedpsych.2018.08.002.

Raven, J.C., Court, J.H., Raven, J., 1992. Standard Progressive Matrices, 1992 edition. Oxford Psychologists Press, Oxford, UK.

Reichwein Zientek, L., Fong, C.J., Phelps, J.M., 2019. Sources of self-efficacy of community college students enrolled in developmental mathematics. J. Furth. High. Educ. 43, 183-200. https://doi.org/10.1080/0309877X.2017.1357071.

Stelzer, F., Richard's, M.M., Andrés, M.L., Vernucci, S., Introzzi, I., 2019. Cognitive and maths-specific predictors of fraction conceptual knowledge. Educ. Psychol. 111, 446-458. https://doi.org/10.1080/01443410.2019.1693508.

Sweller, J., 2010. Element interactivity and intrinsic, extraneous, and germane cognitive load. Educ. Psychol. Rev. 22, 123-138. https://doi.org/10.1007/s10648-010-9128-5.

Tricot, A., Sweller, J., 2014. Domain-specific knowledge and why teaching generic skills does not work. Educ. Psychol. Rev. 26, 265-283. https://doi.org/10.1007/s10648013-9243-1.

Van der Veen, I., Peetsma, T., 2009. The development in self-regulated learning behavior of first-year students in the lowest level of secondary school in The Netherlands. Learn. Indiv Differ 19, 34-46. https://doi.org/10.1016/j.lindif.2008.03.001.

Van Merriënboer, J.J.G., Kirschner, P.A., 2017. Ten Steps to Complex Learning, third ed. Routledge, New York, NY.

Weeks, K.W., Hutton, B.M., Young, S., Coben, D., Clochesy, J.M., Pontin, D., 2013a. Safety in numbers 2: competency modelling and diagnostic error assessment in medication dosage calculation problem-solving. Nurse Educ. Pract. 13, e23-e32. https://doi.org/ 10.1016/j.nepr.2012.10.013.

Weeks, K.W., Hutton, B.M., Young, S., Coben, D., Clochesy, J.M., Pontin, D., 2013. Safety 
in numbers 3: authenticity, Building knowledge \& skills and Competency development \& assessment: the $\mathrm{ABC}$ of safe medication dosage calculation problem-solving pedagogy. Nurse Educ. Pract. 13, e23-e26. http://dx.doi.org/10.1016/j.nepr.2012. 10.013.

Weeks, K.W., Lyne, P., Torrance, C., 2000. Written drug dosage errors made by students: the threat to clinical effectiveness and the need for a new approach. Clin. Effect Nurs. 4 (1), e20-e29. https://doi.org/10.1054/cein.2000.0101.

Wei, W., Yuan, H., Chen, C., Zhou, X., 2012. Cognitive correlates of performance in advanced mathematics. Br. J. Educ. Psychol. 82, 157-181. https://doi.org/10.1111/j. 2044-8279.2011.02049.x.

Wigfield, A., Eccles, J.S., 2000. Expectancy-value theory of achievement motivation.
Contemp. Educ. Psychol. 25, 68-81. https://doi.org/10.1006/ceps.1999.1015.

Wu, J.-H., Tennyson, R.D., Hsia, T.-L., 2010. A study of student satisfaction in a blended elearning system environment. Comput. Educ. 55, 155-164. https://doi.org/10.1016/ j.compedu.2009.12.012.

Xinhao, X., Fengfeng, K., 2016. Designing a virtual-reality-based, gamelike math learning environment. Am. J. Dist. Educ. 30, 27-38. https://doi.org/10.1080/08923647. 2016.1119621.

Zwart, D.P., Van Luit, J.E.H., Noroozi, O., Goei, S.L., 2017. The effects of digital learning material on students' mathematics learning in vocational education. Cogent Educ. 4, 1313581. https://doi.org/10.1080/2331186X.2017.1313581. 